\title{
Analysis on Loose Circle of Surrounding Rock of Large Deformation Soft-Rock Tunnel
}

\author{
Rui Wang, ${ }^{1}$ Yiyuan Liu, ${ }^{1}$ Xianghui Deng $\mathbb{D}^{1},{ }^{1}$ Yu Zhang, ${ }^{1}$ Xiaodong Huang, ${ }^{2}$ and Xiao Ding ${ }^{1}$ \\ ${ }^{1}$ School of Civil and Architecture Engineering, Xi'an Technological University, Xi'an 710021, China \\ ${ }^{2} X i$ 'an Shaanxi Road and Bridge Group Co. Ltd, Xi'an 710000, China \\ Correspondence should be addressed to Xianghui Deng; xianghuideng@xatu.edu.cn
}

Received 5 June 2020; Revised 4 October 2020; Accepted 22 October 2020; Published 17 November 2020

Academic Editor: Hailing Kong

Copyright (c) 2020 Rui Wang et al. This is an open access article distributed under the Creative Commons Attribution License, which permits unrestricted use, distribution, and reproduction in any medium, provided the original work is properly cited.

With the rapid development of tunnel construction in China, deep buried and long tunnel projects are emerging in areas with complex engineering geological conditions and harsh environment, and thus large deformation of tunnels under conditions of high in situ stress and soft rock becomes increasingly prominent and endangers engineering safety. Therefore, it is of great significance to control the deformation and improve the stability of surrounding rock by analyzing the thickness and distribution law of loose circle according to the unique mechanical properties and failure mechanism of surrounding rock of large deformation soft-rock tunnel. Based on unified strength theory, this paper deduces the radius calculation formula of the loose circle by considering the influence of intermediate principal stress. Furthermore, the theoretical calculations and field tests of the loose circle in the typical sections of grade II and III deformation of Yuntunbao tunnel are carried out, and the thickness and distribution law of loose circle of surrounding rock of large deformation soft-rock tunnel is revealed. The results show that the formula based on the unified strength criterion is applicable for a large deformation tunnel in soft rock.

\section{Introduction}

With the development of transportation facilities in western mountainous areas of China, more and more tunnels are built in soft rock areas with high in situ stress. Soft rock is featured by low strength and strong expansibility [1-3], so it is easy to produce large deformation due to high in situ stress extrusion or improper technical measures, which will affect the stability of surrounding rock [4-8]. The deformation is usually characterized by large deformation, fast deformation rate, long duration, various failure forms, and large damage scope, bringing about considerable losses to the project [9-11]. When the tunnel is built in this kind of environment, problems such as large rheology and large displacement are constantly emerging, which will lead to serious underground excavation accidents under complex geological conditions [12-14]. Because the stress redistribution after tunnel excavation will form a ring-shaped fracture zone within a certain range in its section space, that is, the loose circle of surrounding rock [15], of which the distribution range and law have a great influence on the stability of surrounding rock [16-19]. The larger the loose circle is, the worse the stability of surrounding rock is, and the more difficult the tunnel support is. So it is of great significance to study systematically the thickness and distribution law of loose circle of surrounding rock of large deformation soft-rock tunnel for controlling the deformation and improving the stability of surrounding rock.

So far, theoretical analysis and field measurement are mainly adopted in the study of a loose circle of surrounding rock both at home and abroad. Currently, the theoretical research of the radius of the loose circle is mainly in the theory of elastoplastic mechanics and numerical simulation. Dube et al. [20] determined the radius of the "broken zone" by using the graphic method based on the elastic-plastic analysis. Later on, Whitaker determined the size of the loose circle and the amount of convergence generated by the method of mathematical simulation through the data of the laboratory. Based on the "Convergence-Confinement" method, Serrano et al. [21] obtained the mathematical 
expression to determine the radius of the loose circle. Li et al. [22] used the theory of elastic-plastic mechanics to deduce the analytical solutions of stress, displacement, and range of plastic zone in different stages and explained the stress and displacement of surrounding rock in practical engineering. Xia et al. [23] used the finite element method to regress the peak value of the effective stress of the element and revealed the range of the surrounding rock loose circle through numerical simulation. By using the acoustic detector, the changing law of the loose circle under the blasting dynamic load of the tunnel in front of the coal mine driving was obtained. Yu et al. [24] used the maximum axial force of bolt to determine the scope of surrounding rock loose area and plastic area theoretically and put forward the calculation formula of the radius of the plastic area and loose area after the surrounding rock deformation stopped.

For the field test of the radius of the loose circle, many experts and scholars have studied a lot. Toshio Maejima et al. [25] described an evaluation of the loose circle based on monitored stress of rock. At the same time, in observational design and construction procedures, by monitoring the loosening behavior and correctly predicting and analyzing the subsequent behavior of the cavern, the cavern supporting system was optimized. Golebiowski [26] presented using the GPR method for the location of the loose circle in the river embankments. The changeable-offset profiling he proposed in the paper gave wider possibilities in GPR detection of the loose circle distribution in levees than standard, zero-offset, reflection profiling. Czaja [27] determined the methodology of GPR measurements in flood embankments investigation by investigating the nonuniformity of the loose and saturated zones in the flood dike. Hong Dinhpuc [28] studied the excavation damaged zone of the hydropower station EDZ by using the geophysical testing method (acoustic wave and digital borehole camera technology). The results show that the damage of caverns surrounding rock masses is usually induced by the redistribution of stress undisturbed rock mass in the caverns excavation process. Huotari-Halkosaari [29] integrated geophysical and geological research methods to provide information for possible faults and weak zones near the new metro line. For detection of loose zones located in the flood levee, Golebiowski Tomislaw and Malysa Tomasz [30] carried out with the use of short-offset reflection profiling technique, and radargrams were subjected to standard signal processing.

In summary, the thickness of the loose circle of surrounding rock is greatly affected by the buried depth of surrounding rock, initial in situ stress, and support parameters; especially in the large deformation tunnel of soft rock, the thickness of the loose circle is also greatly different. Therefore, it is essential to determine the radius of the loose circle by combining theory with the field test. However, the researches on the radius of the loose circle of large deformation soft rock are still in a relatively scarce stage at present. Based on the systematic classification of large deformations, the thickness formula of the loose circle in surrounding rock of large deformation soft-rock tunnel is derived based on unified strength criterion, and then the thickness and distribution law of loose circle of Yuntunbao tunnel is analyzed with field acoustic wave test.

\section{Concept and Classification of Large Deformation of Soft Rock}

Large deformation of soft rock is caused by the fact that the displacement of surrounding rock cannot be effectively restrained by conventional supporting structure and construction method after the deep buried or expansible surrounding rock meets water, which leads to the deformation far exceeding the allowable range in the code or the reserved range in design (some scholars defined it as the deformation exceeding $3 \%$ of tunnel diameter), and it does not converge for a long time, and even causes large-scale plastic failure.

The large deformation of surrounding rock has obvious characteristics of fluid-plastic deformation and shows progressive expansion characteristic and obvious time effect. It often leads to the destruction of the tunnel support structure, such as cracking and falling of primary support concrete, distortion, and even breaking of the steel frame, causing great difficulties in construction.

Surrounding rocks of large deformation in the soft rock are $\mathrm{V}$-grade. However, there are still significant differences in crown settlement and surrounding convergence values between different tunnels or different sections of the same tunnel. Therefore, it is necessary to systematically classify large deformation of soft rock for the accurate design of tunnel construction method, supporting type, lining type, and thickness and effectively guaranteeing the construction safety and reducing project cost.

Experts and scholars at home and abroad generally divided the classification standard of large deformation of soft rock into two stages: design and construction. In the design stage, one or more factors, such as deformation amount $\left(U_{a}\right)$, relative deformation amount $\left(U_{a} / a\right)$, strengthstress ratio $\left(R_{b} / \sigma_{v}\right)$, and initial in situ stress $\left(\sigma_{v}\right)$, are taken as the index to initially determine the classification standard. Moreover, corresponding design measures for prevention and control are put forward. In the construction stage, the classification standard is further refined and the deformation management standard is put forward according to site geological conditions and construction deformation. At present, the most representative classification standard in China is shown in Table 1.

The internal cause of large deformation of soft-rock tunnel is that the initial stress field has higher tectonic stress and lower rock mass strength. That is, the Strength-Stress ratio $\left(R_{b} / \sigma_{v}\right)$ is relatively small, showing the most intuitive appearance of large deformation. Therefore, the StrengthStress ratio $\left(R_{b} / \sigma_{v}\right)$ and deformation amount of surrounding rock $\left(U_{a}\right)$ are used as indexes to classify large deformation in this paper. Referring to the existing quantitative standards at home and abroad, the classification standard of large deformation of soft rock is shown in Table 2. 
TAвLE 1: Representative classification standards for large deformation of soft rocks in China.

\begin{tabular}{|c|c|c|c|c|c|}
\hline \multirow{2}{*}{ Experts and scholars } & \multirow{2}{*}{ Grade } & \multicolumn{4}{|c|}{ Classification index } \\
\hline & & $\sigma_{v}(\mathrm{MPa})$ & $R_{b} / \sigma_{v}$ & $U_{a}(\mathrm{~cm})$ & $U_{a} / a(\%)$ \\
\hline \multirow{3}{*}{ China railway erju construction [31] } & I & $5 \sim 10$ & $0.33 \sim 0.2$ & - & $4 \sim 7$ \\
\hline & II & $10 \sim 15$ & $0.2 \sim 0.125$ & - & $7 \sim 10$ \\
\hline & III & $>15$ & $<0.125$ & - & $>10$ \\
\hline \multirow{3}{*}{ Xu Linsheng et al. [31] } & I & - & - & $15 \sim 30$ & $1.5 \sim 3$ \\
\hline & II & - & - & $30 \sim 50$ & $3 \sim 5$ \\
\hline & III & - & - & $>50$ & $>5$ \\
\hline \multirow{3}{*}{ Zhang Zhidao [31] } & I & - & - & - & $3 \sim 6$ \\
\hline & II & - & - & - & $6 \sim 10$ \\
\hline & III & - & - & - & $>10$ \\
\hline \multirow{3}{*}{ Liu Zhichun et al. [31] } & I & $5 \sim 10$ & $0.5 \sim 0.25$ & - & $3 \sim 5$ \\
\hline & II & $10 \sim 15$ & $0.25 \sim 0.15$ & - & $5 \sim 8$ \\
\hline & III & $>15$ & $<0.15$ & - & $>8$ \\
\hline \multirow{3}{*}{ Li Guoliang et al. [31] } & I & - & $0.25 \sim 0.15$ & - & $1.5 \sim 3$ \\
\hline & II & - & $0.15 \sim 0.1$ & - & $3 \sim 5$ \\
\hline & III & - & $<0.1$ & - & $>5$ \\
\hline
\end{tabular}

TABle 2: Classification standard for large deformation of soft rock.

\begin{tabular}{lccc}
\hline Surrounding rock classification & I & II & III \\
\hline Strength-stress ratio $\left(R_{b} / \sigma_{\max }\right)$ & $0.5 \sim 0.25$ & $0.15 \sim 0.25$ & $<0.15$ \\
Deformation amount $(\mathrm{cm})$ & $20 \sim 40$ & $40 \sim 60$ & $>60$ \\
Large deformation degree & Slightly large deformation & Medium-large deformation & Severe large deformation \\
\hline
\end{tabular}

\section{Theoretical Calculation of Loose Circle of Surrounding Rock of Large Deformation Soft- Rock Tunnel}

Most large deformation soft-rock tunnels have higher tectonic stress, sometimes even greater than gravity stress. Therefore, the influence of intermediate principal stress on rock mass strength and stress state should be considered in the elastic-plastic analysis. Although the traditional MohrCoulomb strength criterion and Hoek-Brown strength criterion have been matured in the elastic-plastic calculation of loose circle of the surrounding rock, it failed to consider the influence of intermediate principal stress, leading to inaccurate analysis results. The unified strength criterion not only takes the influence of intermediate principal stress into account but could also degenerate into Mohr-Coulomb strength criterion and Hoek-Brown strength criterion, and thus it is widely used in the engineering field. Therefore, the unified strength criterion is adopted for the theoretical calculation of the thickness of the loose circle of large deformation soft-rock tunnel.

3.1. Calculation Model. In the elastic-plastic stress analysis of circular tunnels, solving the plane strain problems, the basic assumptions of the mechanical model are as follows: (1) the tunnel section is equivalent to a circular one with infinite length; (2) the initial in situ stress $P$ is hydrostatic pressure; that is, the lateral pressure coefficient is 1 ; (3) the surrounding rock is homogeneous, isotropic, and incompressible, and the body force effect is not taken into account. The stress state of the surrounding rock is shown in Figure 1.
3.2. Elastoplastic Analysis of Thickness of Surrounding Rock Loose Circle. The unified strength criterion is expressed as follows:

$$
\begin{aligned}
F & =\sigma_{\theta} \frac{1-\sin \varphi}{1+\sin \varphi}-\frac{1}{1+b}\left(b \sigma_{2}+\sigma_{r}\right) \\
& =\frac{2 c \cos \varphi}{1+\sin \varphi}, \sigma_{2} \leq \frac{1}{2}\left(\sigma_{\theta}+\sigma_{r}\right)+\frac{\sin \varphi}{2}\left(\sigma_{\theta}-\sigma_{r}\right), \\
F^{\prime} & =\frac{\left(\sigma_{\theta}+b \sigma_{2}\right)}{1+b} \frac{1-\sin \varphi}{1+\sin \varphi}-\sigma_{r} \\
& =\frac{2 c \cos \varphi}{1+\sin \varphi}, \sigma_{2} \geq \frac{1}{2}\left(\sigma_{\theta}+\sigma_{r}\right)+\frac{\sin \varphi}{2}\left(\sigma_{\theta}-\sigma_{r}\right) .
\end{aligned}
$$

where $c$ is the cohesive force of surrounding rock; $\varphi$ the internal friction angle of surrounding rock; $\sigma_{2}$ the intermediate principal stress; $\sigma_{r}$ the radial stress; $\sigma_{\theta}$ the tangential stress; $b$ the influence coefficient of intermediate principal stress, which represents the coefficient of principal shear stress and normal stress of relevant surface on the degree of influence on material destroy, and the value range is $0 \leq b \leq 1$. The formula [29] for calculation of $b$ is shown as follows:

$$
\left\{\begin{array}{l}
b=\frac{1+\alpha-B}{B-1}, \\
B=\frac{\sigma_{t}}{\tau_{s}} \\
\alpha=\frac{\sigma_{t}}{\sigma_{c}},
\end{array}\right.
$$




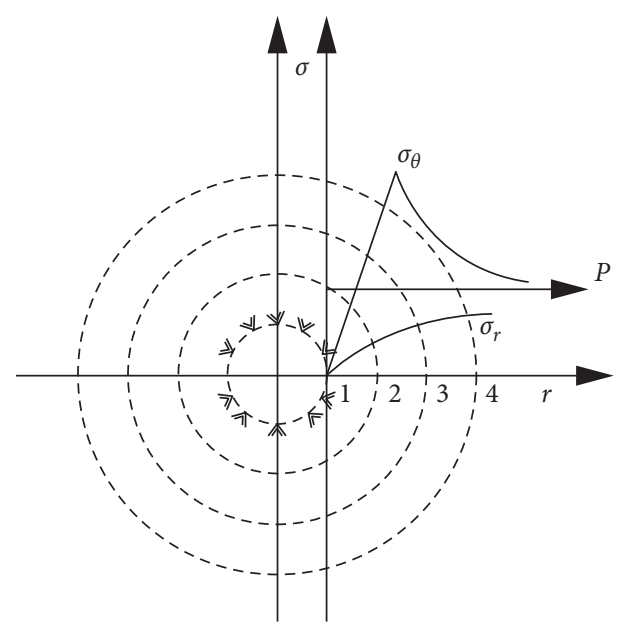

FIGURE 1: Stress diagram of elastic-plastic surrounding rock state.

where $\sigma_{\mathrm{c}}$ is the compressive strength of geotechnical materials; $\sigma_{t}$ the tensile strength; $\tau_{s}$ the shear strength.

For plane strain problems, when the material enters the plastic state, the longitudinal axial stress is the intermediate principal stress $\sigma_{2}$, which approximately takes the average value of radial stress $\sigma_{r}$ and tangential stress $\sigma_{\theta}$. Therefore, the intermediate principal stress in equation (1) can be expressed as follows:

$$
\sigma_{2}=\frac{m}{2}\left(\sigma_{r}+\sigma_{\theta}\right)
$$

where $\mathrm{m}$ is the intermediate principal stress coefficient, and the value range is $0<m \leq 1$. According to the Lev$\mathrm{y}$-Miss hypothesis, for incompressible plastic materials, $\mathrm{m}=1$.

Substituting equation (4) into equation (1), we have the following:

$$
\frac{\sigma_{\theta}-\sigma_{r}}{2}-\frac{\sigma_{\theta}+\sigma_{r}}{2} \frac{2(1+b) \sin \varphi}{2+b(1+\sin \varphi)}=\frac{2(1+b) c \cos \varphi}{2+b(1+\sin \varphi)},
$$

in that way, $\sin \varphi_{t}=2(1+b) \sin \varphi / 2+b(1+\sin \varphi)$, $c_{t}=2(1+b) c \cos \varphi / 2+b(1+\sin \varphi) \cdot 1 / \cos \varphi_{t}$, so equation (5) can be simplified as follows:

$$
F=\frac{\sigma_{\theta}-\sigma_{r}}{2}-\frac{\sigma_{\theta}+\sigma_{r}}{2} \sin \varphi_{t}=c_{t} \cos \varphi_{t}
$$

3.2.1. Basic Equation. The equilibrium equation under axisymmetric condition can be expressed as follows:

$$
\frac{\mathrm{d} \sigma_{r}}{\mathrm{~d} r}+\frac{\sigma_{r}-\sigma_{\theta}}{r}=0
$$

The geometric equation is shown as follows:

$$
\varepsilon_{r}=\frac{\mathrm{d} u}{\mathrm{~d} r}, \varepsilon_{\theta}=\frac{u}{r}
$$

where $r$ is the distance from any point of the surrounding rock to the center of the circle; $u$ the radial displacement.
3.2.2. Elastic Region Analysis. Under the axisymmetric stress condition, the stress in the elastic region can be obtained by stress boundary condition and single-valued condition of displacement:

$$
\left\{\begin{array}{l}
\sigma_{r e}=P_{0}\left(1-\frac{r_{0}^{2}}{r^{2}}\right)+\sigma_{R} \frac{r_{0}^{2}}{r^{2}} \\
\sigma_{\theta e}=P_{0}\left(1+\frac{r_{0}^{2}}{r^{2}}\right)-\sigma_{R} \frac{r_{0}^{2}}{r^{2}}
\end{array}\right.
$$

In addition,

$$
\sigma_{\theta e}+\sigma_{\mathrm{re}}=2 P_{0}
$$

where $r_{0}$ is the excavating radius of the tunnel; $\sigma_{R}$ the radial stress at the elastoplastic interface.

3.2.3. Plastic Region Analysis. Equation (5) can be reorganized as follows:

$$
\sigma_{\theta p}=\frac{1+\sin \varphi_{t}}{1-\sin \varphi_{t}} \sigma_{r p}+\frac{2 c_{t} \cos \varphi_{t}}{1-\sin \varphi_{t}}
$$

By substituting equation (11) into equation (7), it can be arranged as follows:

$$
\frac{1-\sin \varphi_{t}}{2 \sin \varphi_{t}} \ln \left(\frac{2 \sin \varphi_{t}}{1-\sin \varphi_{t}} \sigma_{r p}+\frac{2 c_{t} \cos \varphi_{t}}{1-\sin \varphi_{t}}\right)=\ln r+C_{0},
$$

where $C_{0}$ is integral constant.

Based on the boundary conditions, as $r=r_{0}$, then $\sigma_{r p}=P_{i}$. And, therefore,

$$
C_{0}=\frac{1-\sin \varphi_{t}}{2 \sin \varphi_{t}} \ln \left(\frac{2 \sin \varphi_{t}}{1-\sin \varphi_{t}} \sigma_{r p}+\frac{2 c_{t} \cos \varphi_{t}}{1-\sin \varphi_{t}}\right)-\ln r_{0} .
$$

By substituting equation (13) into equation (12), the equation can be expressed as follows:

$$
\sigma_{r p}=\left(P_{i}+c_{t} \cot \varphi_{t}\right)\left(\frac{r}{r_{0}}\right)^{2 \sin \varphi_{t} / 1-\sin \varphi_{t}}-c_{t} \cot \varphi_{t} .
$$

By substituting equation (14) into equation (11), thus the expression for $\sigma_{\theta p}$ can be obtained as follows:

$$
\sigma_{\theta p}=\frac{1+\sin \varphi_{t}}{1-\sin \varphi_{t}}\left(P_{i}+c_{t} \cot \varphi_{t}\right)\left(\frac{r}{r_{0}}\right)^{2 \sin \varphi_{t} / 1-\sin \varphi_{t}}-c_{t} \cot \varphi_{t} .
$$

Equations (14) and (15) are the expressions of stress in the plastic region of the surrounding rock of the tunnel.

3.2.4. Solution of Radius of Plastic Region and Loose Circle. At the elastic-plastic interface, that is, $r=R_{p}$, both $\sigma_{r}$ and $\sigma_{\theta}$ satisfy the equation of state for both elastic and plastic regions, then $\sigma_{\theta e}=\sigma_{\theta p}, \sigma_{r e}=\sigma_{r p}$. Based on equation (10), 
there is $\sigma_{\theta p}+\sigma_{\mathrm{rp}}=2 P_{0}$. And combining equation (14) with equation (15), the following equation can be obtained:

$$
\begin{aligned}
\left.\left(\sigma_{\theta p}+\sigma_{r p}\right)\right|_{r=R_{p}}= & \frac{2}{1-\sin \varphi_{t}}\left(P_{i}+c_{t} \cot \varphi_{t}\right)\left(\frac{r}{r_{0}}\right)^{2 \sin \varphi_{t} / 1-\sin \varphi_{t}} \\
& -2 c_{t} \cot \varphi_{t}=2 P_{0} .
\end{aligned}
$$

The radius $R_{p}$ of the plastic region and the radial stress $\sigma_{R}$ at the elastic-plastic interface can be obtained with equation (16), as follows:

$$
\begin{aligned}
& R_{p}=r_{0}\left[\frac{\left(1-\sin \varphi_{t}\right)\left(P_{0}+c_{t} \cot \varphi_{t}\right)}{P_{i}+c_{t} \cot \varphi_{t}}\right]^{1-\sin \varphi_{t} / 2 \sin \varphi_{t}}, \\
& \sigma_{R}=P_{0}\left(1-\sin \varphi_{t}\right)-c_{t} \cos \varphi_{t} .
\end{aligned}
$$

According to the definition of the loose circle, the tangential stress of surrounding rock is equal to initial in situ stress on the boundary of the loose circle, that is, $\sigma_{\theta}=P_{0}$. Thus, equation (15) can be simplified as follows:

$$
\begin{aligned}
\sigma_{\theta p}= & \frac{1+\sin \varphi_{t}}{1-\sin \varphi_{t}}\left(P_{i}+c_{t} \cot \varphi_{t}\right)\left(\frac{r}{r_{0}}\right)^{2 \sin \varphi_{t} / 1-\sin \varphi_{t}} \\
& -c_{t} \cot \varphi_{t}=P_{0} .
\end{aligned}
$$

The radius $R_{0}$ of the loose circle is solved through the above formulas, and it can be expressed in the following form:

$$
R_{0}=r_{0}\left[\frac{\left(P_{0}+c_{t} \cot \varphi_{t}\right)\left(1-\sin \varphi_{t}\right)}{\left(P_{i}+c_{t} \cot \varphi_{t}\right)\left(1+\sin \varphi_{t}\right)}\right]^{1-\sin \varphi_{t} / 2 \sin \varphi_{t}} .
$$

Formula (19) shows that the radius $R_{0}$ of the loose circle is related to the tunnel excavating radius $r_{0}$, rock mass strength $c$ and $\varphi$, intermediate principal stress $b$, initial in situ stress field $P_{0}$, and support reaction $P_{\mathrm{i}}$.

\section{Engineering Application}

4.1. Engineering Situation. The newly built Yuntunbao Tunnel is the dominant engineering of the Chengdu-Lanzhou Railway Dedicated Passenger Line located near Anguan Village, Anhong Township, Songpan County, Aba Prefecture, Sichuan Province. The tunnel with a length of $22,923.419 \mathrm{~m}$ starts at the mileage DK213 + 350 at the entrance and ends at the mileage DK236 + 390 at the exit. It is a superlong single-tunnel double-track tunnel. The excavation span is $15.3 \mathrm{~m}$ and height $13.99 \mathrm{~m}$, and the inner contour arch wall is a single-center circle with a radius of $8.5 \mathrm{~m}$. The clearance section is shown in Figure 2. The tunnel is divided into seven transverse tunnels and one outlet work area for construction. No. 7 transverse tunnel passes through the Shidaguan arc structure belt, and it is located in the front arc area of the Jiaochang mountain-shape structural belt. The tunnel runs roughly in parallel with the Minjiang fault zone, and it is seriously affected by regional faults, with the development of small and medium-sized folds, rock fragmentation, and joint development. After geological surveying and mapping and drilling, some unfavorable geological effects such as landslides and debris flows exist in the tunnel site, and high stress with maximum principal stress of $10 \mathrm{MPa}$ exists in the deep burying section. The bulk of surrounding rock is carbonaceous phyllite, mainly composed of sericite, chlorite, and quartz. The fine-grained scales have crystalline texture, low strength, thin-layer, poor integrity, and powder after excavation. Large deformation of soft rock occurs during construction, even serious invasion of initial support and distortion, and fracture of structural steel frames, among which the section DK234 + 190 DK234 + 350 is the most serious, as shown in Figure 3.

4.2. Theoretical Calculation. The conclusion that the tunnel section with large deformation is $\mathrm{V}$-grade surrounding rock can be obtained based on-site geological survey and laboratory test. According to the Code for Design of Railway Tunnel (TB 10003-2016) and geological conditions, the initial support design parameters of the Yuntunbao Tunnel are shown in Table 3.

The large deformation of Yuntunbao Tunnel is classified according to Table 2, and theoretical calculation of surrounding rock loose circle is carried out on large deformation grade II DK234 + 205 section and large deformation grade III DK234 + 318 section of soft rock in No. 7 transverse tunnel, in order to make a profound study about the influence of large deformation of soft rock on the loose circle of Yuntunbao Tunnel. The relevant mechanical parameters of surrounding rock based on field tests are shown in Table 4. Gravity stress is taken as initial in situ stress. According to the Code for Design of Railway Tunnel (TB 10003-2016), the vertical surrounding rock pressure at the arch of the deepburied tunnel is calculated by formula $q=\gamma \times 0.45 \times 2^{s-1} \times[1+i(B-5)]$, and the horizontal pressure is calculated by the uniform load formula $e=\lambda q$. From the measured results, it is known that there is high in situ stress in this section, so $\lambda=1.2$. Meanwhile, the relative mechanical parameters of surrounding rock in Table 4 , such as compressive strength $\sigma_{\mathrm{c}}$, compressive strength $\sigma_{\mathrm{t}}$, and shear strength $\tau_{s}$, are introduced into formula (3), and the influence coefficient of intermediate principal stress $b$ is obtained. The related calculation results are shown in Table 5.

Formula (19) shows that the radius of loose circle $R_{0}$ is related to the excavation radius of tunnel $r_{0}$, rock mass strength $c$ and $\varphi$, intermediate principal stress $b$, and initial in situ stress field $P_{0}$ are related to support reaction $P_{i}$. In practical engineering, the excavation radius, lithology, and initial stress state of the tunnel have been determined, and the thickness of the loose circle can only be affected by 


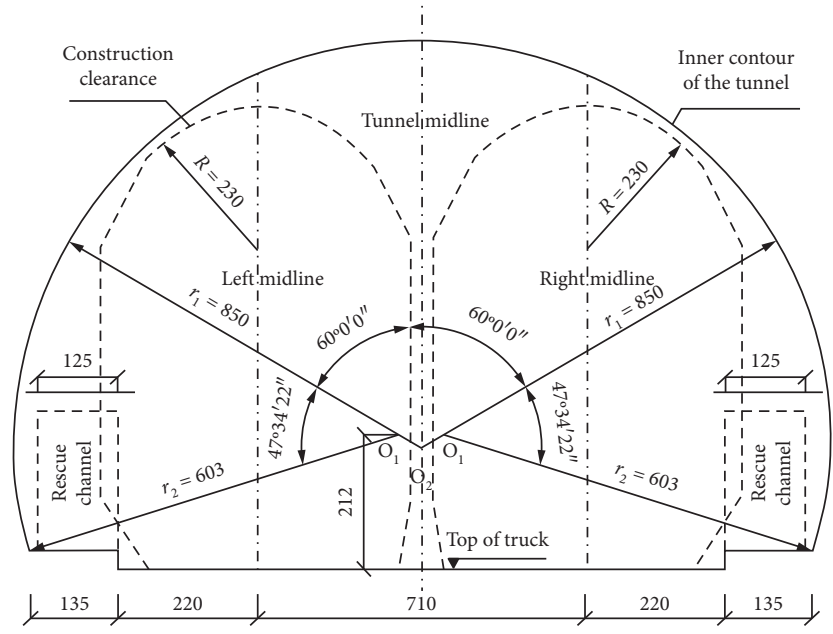

FIgURE 2: Tunnel clearance section.

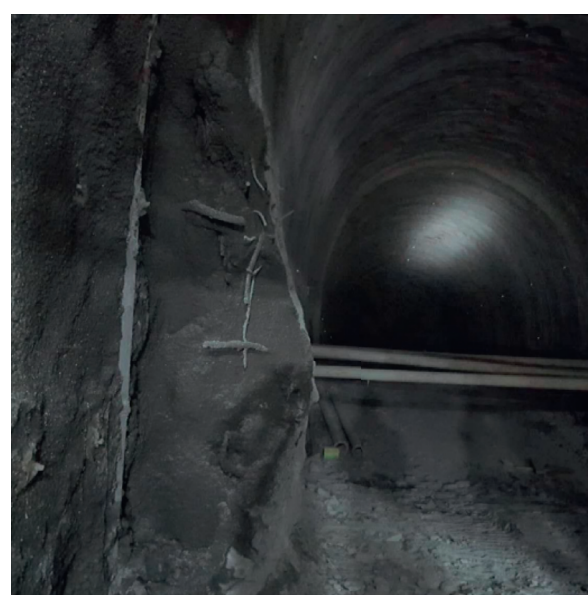

(a)

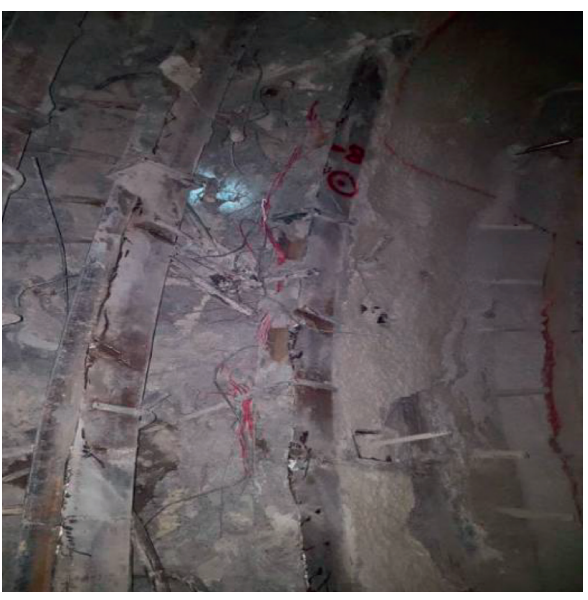

(b)

FIgURE 3: Failure form of initial support. (a) Severe beyond-limit deformation of initial support. (b) Distortion of structural steel frames.

TABLE 3: Initial support parameters table.

\begin{tabular}{lcccc}
\hline Surrounding rock grade & C30 shotcrete $(\mathrm{cm})$ & Mesh reinforcement $(\mathrm{cm})$ & Anchor $(\mathrm{cm})$ & Steel frames $(\mathrm{cm})$ \\
\hline$V$ & 25 & $\phi 8 @ 20 \times 20$ & $L=400, \phi 22 @ 120 \times 100$ & I20b@80 \\
\hline
\end{tabular}

TABLE 4: Relevant mechanical parameters of surrounding rock.

\begin{tabular}{lcccccc}
\hline Cross section mileage & Cohesion c $(\mathrm{kPa})$ & $\begin{array}{c}\text { Internal friction } \\
\text { angle } \varphi\left(^{\circ}\right)\end{array}$ & $\begin{array}{c}\text { Bulk density } \\
\gamma\left(\mathrm{kN} / \mathrm{m}^{3}\right)\end{array}$ & $\begin{array}{c}\text { Compressive } \\
\text { strength } \sigma_{c}(\mathrm{MPa})\end{array}$ & $\begin{array}{c}\text { Compressive } \\
\text { strength } \sigma_{t}(\mathrm{MPa})\end{array}$ & $\begin{array}{c}\text { Shear strength } \\
\tau_{s}(\mathrm{MPa})\end{array}$ \\
\hline DK234+205 & 31 & 32 & 22 & 4.98 & 0.77 & 0.68 \\
DK234+318 & 30 & 33 & 22 & 4.83 & 0.76 & 0.67 \\
\hline
\end{tabular}

changing the support reaction $P_{i}$. Therefore, the thickness of the loose circle caused by different bearing capacity ratios of the initial support structure in surrounding rock pressure is calculated separately. The calculation results of the thickness of the loose circle of the typical section are shown in Table 6, and the curve is drawn, as shown in Figure 4. 
TABLE 5: Calculation table of surrounding rock pressure.

\begin{tabular}{|c|c|c|c|c|c|c|c|c|}
\hline $\begin{array}{l}\text { Cross section } \\
\text { mileage }\end{array}$ & $\begin{array}{c}\text { Large } \\
\text { deformation } \\
\text { grade } \\
\end{array}$ & Area & $\begin{array}{c}\text { Buried } \\
\text { depth } h(\mathrm{~m})\end{array}$ & $\begin{array}{c}\text { Excavation } \\
\text { height } H_{\mathrm{t}}(\mathrm{m})\end{array}$ & $\begin{array}{l}\text { Lateral pressure } \\
\text { coefficient } \lambda\end{array}$ & $\begin{array}{c}\text { Influence coefficient } \\
\text { of intermediate } \\
\text { principal stress b }\end{array}$ & $\begin{array}{l}\text { Initial in } \\
\text { situ stress } \\
\mathrm{P}(\mathrm{kPa}) \\
\end{array}$ & $\begin{array}{c}\text { Surrounding } \\
\text { rock pressure } \\
\mathrm{P}(\mathrm{kPa}) \\
\end{array}$ \\
\hline DK234 + 205 & II-grade & Vault & 200 & 13.99 & 1.2 & 0.168 & 4400 & 321.552 \\
\hline DN234+205 & 11-grade & Side wall & 200 & 3.99 & 1.2 & 0.108 & 5280 & 385.682 \\
\hline DK234 + 318 & III-grade & $\begin{array}{c}\text { Vault } \\
\text { Side wall }\end{array}$ & 250 & 13.99 & 1.2 & 0.171 & 5500 & 321.552 \\
\hline
\end{tabular}

TABLE 6: The calculation values of loose circles of grade II and III large deformation section (m).

\begin{tabular}{|c|c|c|c|c|c|c|c|c|c|c|c|c|}
\hline \multirow{2}{*}{ Cross section mileage } & \multirow{2}{*}{ Area } & \multicolumn{11}{|c|}{ Thickness of loose circle at different bearing capacity ratios of the support structure $R_{0}$} \\
\hline & & 0 & $10 \%$ & $20 \%$ & $30 \%$ & $40 \%$ & $50 \%$ & $60 \%$ & $70 \%$ & $80 \%$ & $90 \%$ & $100 \%$ \\
\hline \multirow{2}{*}{ DK234+ 205} & & 24.08 & 18.02 & 14.64 & 12.39 & 10.75 & 9.47 & 8.45 & 7.61 & 6.89 & 6.27 & 5.73 \\
\hline & Side & 26.59 & 19.19 & 15.35 & 12.88 & 11.11 & 9.76 & 8.68 & 7.80 & 7.05 & 6.41 & 5.85 \\
\hline \multirow{2}{*}{ DK234 + 318} & & 24.66 & 18.52 & 15.15 & 12.92 & 11.30 & 10.04 & 9.03 & 8.20 & 7.49 & 6.88 & 6.34 \\
\hline & Side wall & 27.06 & 20.00 & 15.81 & 13.37 & 11.63 & 10.31 & 9.25 & 8.38 & 7.64 & 7.01 & 6.45 \\
\hline
\end{tabular}

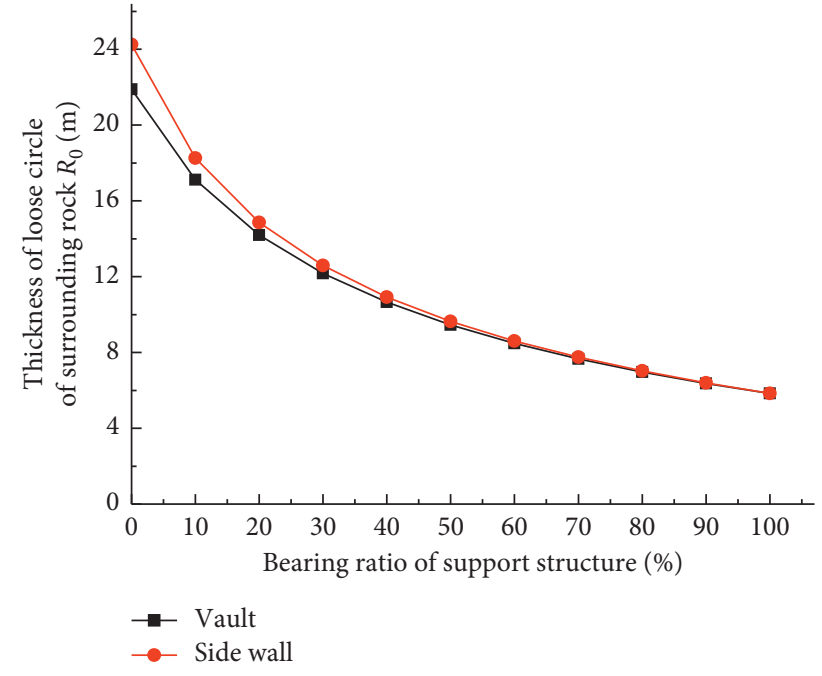

(a)

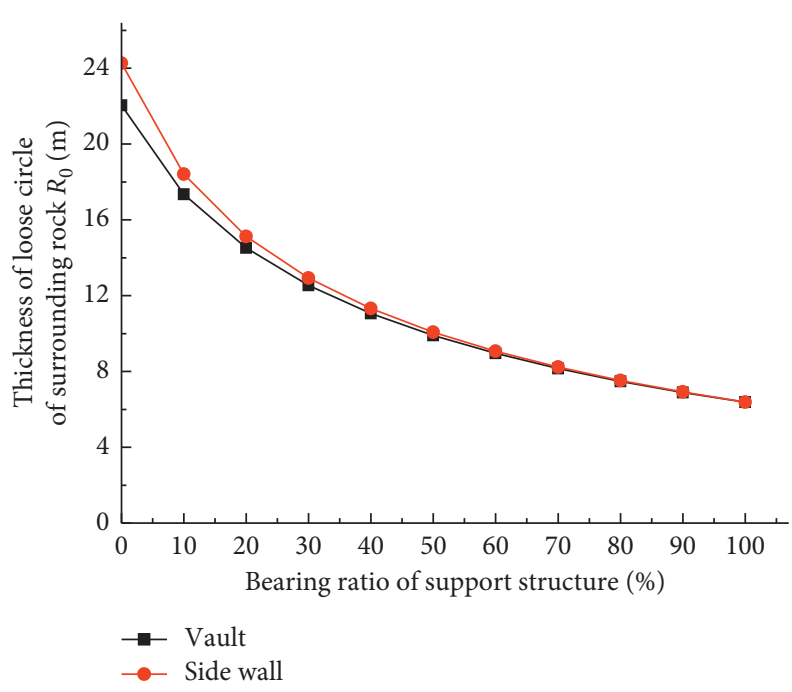

(b)

FIgURE 4: The curve of theoretical calculation of loose circle. (a) DK234+205 section. (b) DK234+318 section.

From Table 6 and Figure 4, it can be concluded that

(1) The higher the large deformation grade of soft rock, the worse the quality of surrounding rock and the thicker the loose circle.

(2) As a whole, there is little difference in the distribution of the loose circles of surrounding rock of tunnel on cross sections. Still, due to the influence of high in situ stress on the initial in situ stress field, the phenomenon that loose circle of the side wall is slightly larger than that of the vault.

(3) With the increase of support resistance $P_{i}$ (i.e., the ratio of support structure bearing capacity increases), the theoretical calculation radius of loose circle decreases gradually.

\subsection{Field Test}

4.3.1. Test Scheme. RSM-SY5 (T) nonmetallic acoustic wave test detector produced by Zhongyan in Wuhan was used to test the loose circle of surrounding rock. DK234+205 section of grade II soft rock with large deformation and DK234 + 318 section of grade III soft rock with large deformation were selected for testing. Both sections were selected from the No.7 cross tunnel of the Yuntunbao tunnel. Considering the surrounding rock condition, cross section area, reliability of data, operability, and cost of test, four test holes are laid on each test section, located on the left and right sides of the sidewall $2 \mathrm{~m}$ and $5 \mathrm{~m}$ away from the track surface of the tunnel. The diameter and depth of the test holes are $40 \mathrm{~mm}$ and $10 \mathrm{~m}$, respectively, which are 


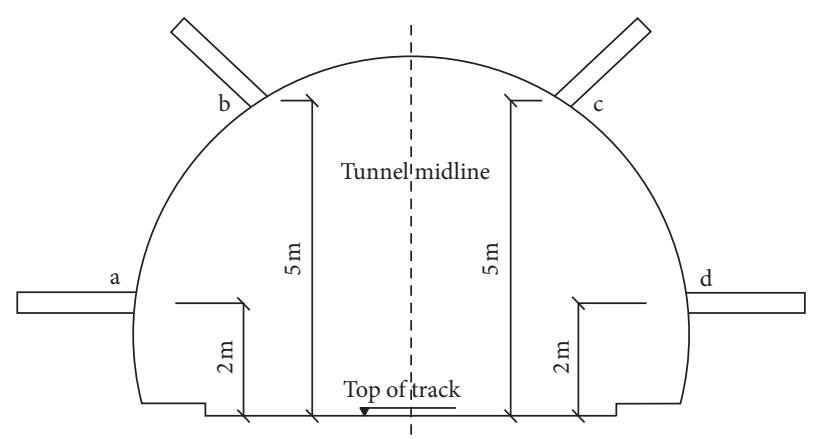

Figure 5: Hole layout.

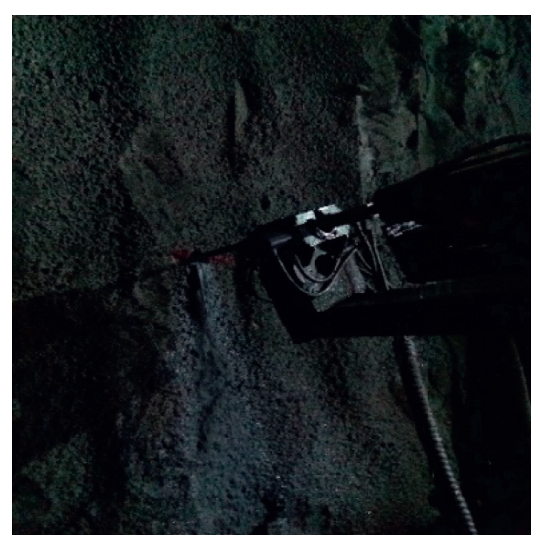

(a)

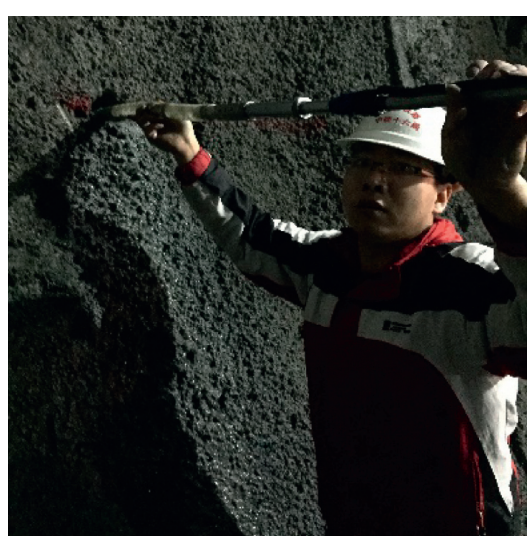

(b)

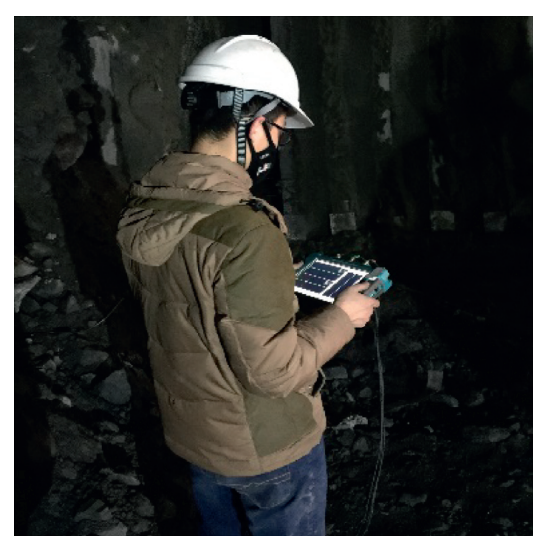

(c)

Figure 6: Field test of the loose circle. (a) Drilling holes, (b) installing probes, (c) collecting data.

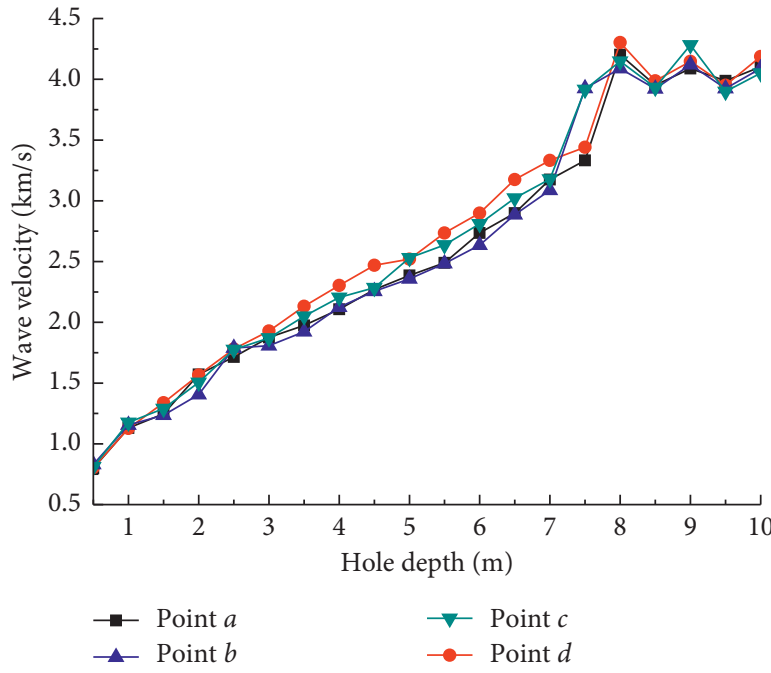

(a)

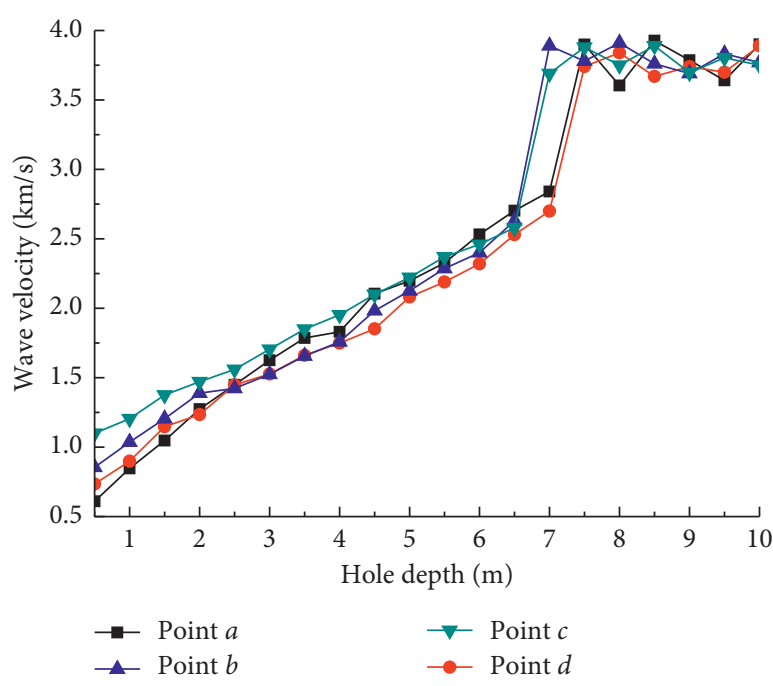

(b)

Figure 7: Hole depth-wave velocity curve of sections. (a) DK234+205 section. (b) DK234+ 318 section.

perpendicular to the excavation face. The locations of test holes are shown in Figure 5.

The field test is divided into five steps [32]: (1) drilling; (2) cleaning; (3) putting a probe into the testing hole; (4) injection; (5) moving measuring rod and starting the test, pulling out the rod by $0.5 \mathrm{~m}$ at a time until the whole rod is consumed to complete the test. Part of the operation process of the engineering site is shown in Figure 6. 
TABLE 7: Measured values of loose circles and surrounding rock pressures of typical section (m).

\begin{tabular}{|c|c|c|c|c|c|}
\hline \multirow{2}{*}{ Cross section mileage } & \multirow{2}{*}{ Test items } & \multicolumn{4}{|c|}{ Hole location } \\
\hline & & 1 & 2 & 3 & 4 \\
\hline \multirow{2}{*}{$\mathrm{DK} 234+205$} & Loose circle $(\mathrm{m})$ & $7 \sim 7.5$ & $6.5 \sim 7$ & $6.5 \sim 7$ & $7 \sim 7.5$ \\
\hline & Surrounding rock pressure $(\mathrm{kPa})$ & 304.7 & 259.3 & 241.2 & 288.4 \\
\hline \multirow{2}{*}{$\mathrm{DK} 234+318$} & Loose circle $(\mathrm{m})$ & $7.5 \sim 8$ & $7 \sim 7.5$ & $7 \sim 7.5$ & $7.5 \sim 8$ \\
\hline & Surrounding rock pressure $(\mathrm{kPa})$ & 322.6 & 279.1 & 251.3 & 307.7 \\
\hline
\end{tabular}

4.3.2. Analysis of Test Results. The longitudinal wave velocity of surrounding rock at different depths is measured in typical sections. The hole depth-wave velocity curves of each measuring point are plotted, as shown in Figure 7.

In Figure 7, the position where longitudinal wave velocity of rock has catastrophe occurrences is taken as the boundary of the loose circle, so the loose circle of the sidewall (points a and d) of DK234 + 205 section of grade II soft rock with large deformation ranging from $7 \mathrm{~m}$ to $7.5 \mathrm{~m}$, the loose circle of the vault (points $b$ and c) ranging from $6.5 \mathrm{~m}$ to $7 \mathrm{~m}$, the loose circle of the sidewall (points a and d) of grade III soft rock with large deformation ranging from $7.5 \mathrm{~m}$ to $8 \mathrm{~m}$, and the loose circle of the vault (points $b$ and c) is $7.7 \mathrm{~m}$ to 7 . $5 \mathrm{~m}$, as shown in Table 7 .

From Table 7, the pressure of surrounding rock measured at each measuring point is about $80 \%$ of the theoretical value of surrounding rock pressure, and the values of thickness of loose circle measured at section DK234 + 205 of grade II and section DK234 + 318 of grade III soft rock with large deformation are basically consistent with the theoretical calculation values when supporting structure bears $80 \%$ of surrounding rock pressure. It shows that the theoretical calculation results are reliable, and according to the existing construction scheme, the surrounding rock stress has been released by $20 \%$ when the initial support construction is completed. At the same time, by monitoring and measuring, the peripheral convergence of section DK234 + 205 of grade II and section DK234 + 318 of grade III soft rock with large deformation is $475 \mathrm{~mm}$ and $662 \mathrm{~mm}$, respectively, which are far beyond the standard and should be classified as large deformation. The main cause of large deformation is due to the supporting structure, which is not constructed in time and the insufficient length of the bolt which cannot provide enough support reaction.

\section{Conclusions}

Based on unified strength criterion, in this paper, there is the deduction of the formula for calculating the radius of the loose circle of surrounding rock in the tunnel, theoretical calculation, and field test of surrounding rock loose circle for typical sections of grade II and III soft rock with large deformation which is carried out in Yuntunbao Tunnel and analyzes the distribution range and law of loose circle of surrounding rock in large deformation tunnel of soft rock. The main conclusions are as follows:

(1) Based on the objective fact that high in situ stress exists in large deformation tunnel in soft rock, a formula for calculating the radius of the loose circle is derived with unified strength criterion and considering the influence of intermediate principal stress on the stress state of surrounding rock.

(2) In a large deformation tunnel of soft rock, with the upgrade of large deformation, the quality of surrounding rock becomes worse. Supporting resistance decreases and the thickness of the loose circle increases continuously. Moreover, due to the influence caused by high in situ stress, the distribution of the loose circle on the cross section is larger than that on side wall of the arch.

(3) The field measurement results of the loose circle of surrounding rock in the Yuntunbao tunnel are close to the theoretical calculation values when the supporting structure bears $80 \%$ of surrounding rock pressure. The thickness of the loose circle of the vault and the sidewall of grade II large deformation section is from $6.5 \mathrm{~m}$ to $7.0 \mathrm{~m}$ and $7.0 \mathrm{~m}$ to $7.5 \mathrm{~m}$, respectively, and that of grade III large deformation section is from $7.0 \mathrm{~m}$ to $7.5 \mathrm{~m}$ and $7.5 \mathrm{~m}$ to $8.0 \mathrm{~m}$, respectively. It shows that the formula for calculating the radius of the loose circle based on the unified strength criterion is applicable for a large deformation tunnel in soft rock.

(4) The peripheral convergences of grade II large deformation section and grade III large deformation section of Yuntunbao Tunnel reach $475 \mathrm{~mm}$ and $662 \mathrm{~mm}$, respectively, which are far above the limit and should be classified as large deformation. The length of the bolt can be optimized according to the thickness of the loose circle, so as to provide sufficient support reaction, which controls the displacement of surrounding rock and ensures the safety of the structure.

\section{Data Availability}

The raw/processed data required to reproduce these findings cannot be shared at this time as the data also form part of an ongoing study.

\section{Conflicts of Interest}

The authors declare that they have no conflicts of interest.

\section{Acknowledgments}

This research was financially supported by the Natural Science Foundation (2017JM5136) by the Science and 
Technology Department of Shaanxi Province, the Special Scientific Research Program (18JK0402) by the Education Department of Shaanxi Province, the Key Research and Development Program (2018SF-391) by Shaanxi Province, the Housing and Urban-Rural Construction Foundation (2017-K55) by the Housing and Urban-Rural Department of Shaanxi Province, the Science and Technology Department of Xi'an (GXRC008CG009-GXYD8.2), and Special Scientific Research Project of Shaanxi Provincial Department of Education (19JK0399).

\section{References}

[1] O. Kenzo, T. Tatsuya, and T. Fumio, "Deformation characteristics of sedimentary soft rock evaluated by field and laboratory tests and full-scale behaviour," Journal of the Society of Materials Science Japan, vol. 44, pp. 856-861, 1995.

[2] C. Yit-Jin and C. Sheng, Evaluation of Influence Parameters for Soft Rock Tunnel, Geotechnical Special Publication, Denver, CO, USA, 2007.

[3] M. Iwata, A. Yashima, and K. Sawada, "Local behavior of pore water pressure during plane-strain compression of soft rock," Springer Series in Geomechanics and Geoengineering, vol. 5, pp. 211-227, 2011.

[4] O. Kenzo, T. Tatsuya, and T. Fumio, "Deformation characteristics of sedimentary soft rock evaluated by full-scale excavation, field and laboratory investigation and liner backanalysis," Proceedings of the Japan Society of Civil Engineers, vol. 487, pp. 177-186, 1994.

[5] T. Fumio and L. Wang, "Brief review of the strength and deformation characteristics of sedimentary soft rock," Chinese Journal of Rock Mechanics and Engineering, vol. 22, pp. 872-893, 2003.

[6] D. C. Peckley and T. Uchimura, "Strength and deformation of soft rocks under cyclic loading considering loading period effects," Soils and Foundations, vol. 49, no. 1, pp. 51-62, 2009.

[7] D. Sterpi and G. Gioda, "Visco-Plastic behaviour around advancing tunnels in squeezing rock," Rock Mechanics and Rock Engineering, vol. 42, no. 2, pp. 319-339, 2009.

[8] S. Archer and V. Rasouli, "A log based analysis to estimate mechanical properties and in-situ stresses in a shale gas well in North Perth Basin,"vol. 81, pp. 163-174, in Proceedings of the 1st International Conference on Petroleum and Mineral Resources, vol. 81, pp. 163-174, WIT Press, Kurdistan, Iraq, 2013.

[9] M. S. A. Siddiquee and A. Hamdi, "A time-dependent double hardening model for soft rock," Advances in Civil Engineering, vol. 2019, no. 2, pp. 1-18, 2019.

[10] L. R. Sousa, Learning With Accidents And Damage Associated To Underground Works, pp. 7-39, Taylor and Francis - Balkema, Oxfordshire, UK, 2006.

[11] R. L. Sousa and H. H. Einstein, "Risk analysis during tunnel construction using Bayesian networks: porto Metro case study," Tunnelling and Underground Space Technology, vol. 27, no. 1, pp. 86-100, 2012.

[12] M. C. Acar and B. Kaya, "Models to estimate the elastic modulus of weak rocks based on least square support vector machine," Arabian Journal of Geoences, vol. 13, no. 14, 2020.

[13] Y. Xue, T. Teng, F. Dang, Z. Ma, S. Wang, and H. Xue, "Productivity analysis of fractured wells in reservoir of hydrogen and carbon based on dual-porosity medium model," International Journal of Hydrogen Energy, vol. 45, no. 39, pp. 20240-20249, 2020.
[14] Y. Xue, P. G. Ranjith, F. Dang et al., "Analysis of deformation, permeability and energy evolution characteristics of coal mass around borehole after excavation," Natural Resources Research, vol. 29, pp. 1-19, 2020.

[15] Q. Zeng, E. Wang, and S. Wang, "Comparison between plastic radius around a circular opening derived from Hoek-Brown failure criterion and calculated through modified Fenner formula," Journal of Shenyang Jianzhu University (Natural Science), vol. 24, pp. 933-938, 2008.

[16] L. L. Ngueyep Mambou, J. Ndop, and J.-M. B. Ndjaka, "Numerical investigations of stresses and strains redistribution around the tunnel: influence of transverse isotropic behavior of granitic rock, in situ stress and shape of tunnel," Journal of Mining Science, vol. 51, no. 3, pp. 497-505, 2015.

[17] X. Zhang, F. M. He, and S. G. XuLi, "Study on the large deformation characteristics and disaster mechanism of a thinlayer soft-rock tunnel," Advances in Civil Engineering, vol. 2020, no. 6, 15 pages, Article ID 8826337, 2020.

[18] I. Tao, N. Vlachopoulos, and M. S. Diederichs, "Assessing fracturing mechanisms and evolution of excavation damaged zone of tunnels in interlocked rock masses at high stresses using a finite-discrete element approach," Journal of Rock Mechanics and Geotechnical Engineering, vol. 11, no. 4, pp. 701-722, 2019.

[19] I. Vazaios, N. Vlachopoulos, and M. S. Diederichs, "Mechanical analysis and interpretation of excavation damage zone formation around deep tunnels within massive rock masses using hybrid finite-discrete element approach: case of Atomic Energy of Canada Limited (AECL) Underground Research Laboratory (URL) test tunnel," Canadian Geotechnical Journal, vol. 56, no. 1, pp. 35-59, 2019.

[20] X. Zhou and G. Song, "Theory research situation of foreign surrounding rock loose circle support theory," Mine Construction Technology, vol. 6771 pages, 1994.

[21] A. Serrano, C. Olalla, and I. Reig, "Convergence of circular tunnels in elastoplastic rock masses with non-linear failure criteria and non-associated flow laws," International Journal of Rock Mechanics and Mining Sciences, vol. 48, no. 6, pp. 878-887, 2011.

[22] L. Ming, X. Mao, Y. Yu et al., "Stress and deformation analysis on deep surrounding rock at different time stages and its application," International Journal of Mining Science and Technology, vol. 22, pp. 301-306, 2012.

[23] H. B. Xia, Y. Xu, and Y. Zhang, "Numerical simulation and experimental analysis of roadway surrounding rock loose circle under blasting vibration," in Proceedings of the 2013 4th International Conference on Digital Manufacturing and Automation, pp. 850-854, IEEE Computer Society, Shangdong, China, 2013.

[24] Y. X. Yu, B. P. Chen, T. Zhang et al., "Back analysis on deformation and failure zone distribution laws of surrounding rock in deep-buried soft rock tunnel," Journal of Railway Engineering Society, vol. 34, pp. 46-52, 2017.

[25] T. Maejima, H. Morioka, T. Mori, and K. Aoki, "Evaluation of loosened zones on excavation of a large underground rock cavern and application of observational construction techniques," Tunnelling and Underground Space Technology, vol. 18, no. 2-3, pp. 223-232, 2003.

[26] T. Golebiowski, "Changeable-offset GPR profiling for loose zones detection in levees," in Proceedings of the 14th European Meeting of Environmental and Engineering Geophysics of the Near Surface Geoscience Division of EAGE, European Association of Geoscientists and Engineers, Porto, Portugal, 2008. 
[27] K. Czaja, "Application of GPR and computer modelling in flood embankment investigation," in Proceedings of the 75th European Association of Geoscientists and Engineers Conference and Exhibition, European Association, pp. 6246-6248, London, UK, 2013.

[28] D. P. Hoang, G. L. Xu, Z. P. Li et al., "Investigation of failure mechanism and process on excavation damaged zone/Disturbed zone (EDZ) of underground engineering in rock," in Proceedings of the ISRM VietRock 2015 International Workshop, pp. 1-9, International Society for Rock Mechanics, Hanoi, Vietnam, 2015.

[29] T. K. T. Huotari-Halkosaari, M. H. Wennerstöm, and I. A. S. Suppala, "Study of integrated geophysical and geological research methods on mapping weakness structures in bedrock at urban areas," in Proceedings of the Near Surface Geoscience 2016-22nd European Meeting of Environmental and Engineering Geophysics, European Association of Geoscientists and Engineers, 2016.

[30] G. Tomislaw and M. Tomasz, "Application of GPR method for detection of loose zones in flood levee. 1st conference of the international water association IWA," EDP Sciences, vol. 30, pp. 1-11, 2018.

[31] G. Li, Z. Liu, and Y. Zhu, "On the large squeezing deformation law and classification criteria for the Lanzhou-Chongqing Railway Tunnels in soft and high geostress rocks," Modern Tunnelling Technology, vol. 52, pp. 62-68, 2015.

[32] Ministry of Housing and Urban-Rural Development of the People's Republic of China and General Administration of Quality Supervision, Inspection and Quarantine of the People's Republic of China, Standard for Test Methods of Engineering Rock Mass (GB/T 50266-2013), China Planning Press, Beijing, China, 2013. 